Please do not remove this page

RMIT

UNIVERSITY

\title{
Informal translation, post-cinema and global media flows
}

Dwyer, Tessa; Lobato, Ramon

https://researchrepository.rmit.edu.au/esploro/outputs/9921859917501341/filesAndLinks?institution=61RMIT_INST\&index=null

Dwyer, T., \& Lobato, R. (2016). Informal translation, post-cinema and global media flows. In The State of Post-Cinema: Tracing the Moving Image in the Age of Digital Dissemination (pp. 127-145). Palgrave. https://doi.org/10.1057/978-1-137-52939-8_8

Document Version: Published Version

Published Version: https://doi.org/10.1057/978-1-137-52939-8_8

Repository homepage: https://researchrepository.rmit.edu.au

(c) The Author(s) 2016

Downloaded On 2023/04/26 21:35:22 +1000

Please do not remove this page 
Thank you for downloading this document from the RMIT Research Repository.

The RMIT Research Repository is an open access database showcasing the research outputs of RMIT University researchers.

RMIT Research Repository: http://researchbank.rmit.edu.au/

\section{Citation:}

Dwyer, T and Lobato, R 2016, 'Informal translation, post-cinema and global media flows' in Malte Hagener, Vinzenz Hediger and Alena Strohmaier (ed.) The State of Post-Cinema: Tracing the Moving Image in the Age of Digital Dissemination, Palgrave, United Kingdom, pp. 127-145.

See this record in the RMIT Research Repository at:

https://researchbank.rmit.edu.au/view/rmit:39462

Version: Published Version

Copyright Statement:

(C) The Author(s) 2016

\section{Link to Published Version:}

https://dx.doi.org/10.1057/978-1-137-52939-8_8 


\title{
Informal Translation, Post-Cinema and Global Media Flows
}

\author{
Tessa Dwyer and Ramon Lobato
}

A good way to get a sense of the current state of international cinema is to spend some time on a sub website, where Internet users share homemade or pirated subtitles for popular movies. OpenSubtitles, Subscene, Addic7ed, Subdivx, YIFYsubtitles - these and many other sites offer free, downloadable SRT (SubRip Text) and SUB (Subviewer) files, of variable quality and provenance, to be played alongside movies using open-source media players such as VLC Player. Here you will find a vast range of subtitles in an equally vast range of languages: AMERICAN SNIPER (2014) in Bahasa and Farsi, Dhoom 3 (2013) in Arabic, Malay, and Vietnamese, and Snowpiercer (2013) in Bengali. You will also encounter lively forums where users request uploads of particular movies, discuss the quality of different translations, promote their own subbing efforts, and trade insults with rival subbers.

Sub sites are quintessential spaces of global cinema, in the sense that they bring together characteristic features of our technologically and spatially convergent mediascape. The wild diversity of content (ranging from

\section{T. Dwyer $(\bowtie)$}

Film and Screen Studies, School of Media, Film and Journalism, Monash University, Melbourne, Australia

R. Lobato

RMIT University, Melbourne, Australia

(C) The Author(s) 2016 
obscure anime to new blockbuster movies, TV series and music videos), the increasing audibility of multilingual publics, the ethical drama of fan labor and self-exploitation, corporate/community tensions, and, not least, rampant copyright violation and piracy, understood here as a basic condition of this transnational cultural infrastructure-all these issues take tangible form in the sub scene, where the uneven content flows and discrepant passions that drive global cinema circulation are rendered visible.

In recent years a number of scholars have begun to analyze the dynamics of this vast translation machine (Leonard, "Progress"; Jenkins; Denison; Dwyer, "Fansub Dreaming", "Multilingual Publics"; Ito; Hemmungs Wirtén, "Swedish Subtitling"; Mendes Moreira de Sa). The research has been mostly concerned with television audiences, perhaps because the most passionate and prolific subbing activity is done by fans of TV showsespecially US and East Asian dramas but also anime, which holds special significance within the history of informal subbing. Translation scholars (Perez-Gonzalez; O'Hagan; Orrego-Carmona) have also begun to study the sub scene, intrigued by what they see as a new frontier for transcultural engagement and a corresponding expansion of the boundaries of everyday translation activity. Together, this body of research is starting to document and theorize a fully scalable, global infrastructure for informal translation, one that raises important questions about transculturation, user innovation and fan labor $(\mathrm{Hu})$.

What do informal translation systems like this have to do with the topic of this book - the post-cinematic moment? Post-cinema-if understood as the ontology of the moving image in the wake of cinema's digital dethronement, as it assumes a new kind of position alongside video games, Internet media, digital television, video art, and so on-is a narrative for describing the decomposition and re-arrangement of a media ecology from the perspective of its once-dominant medium. In Stam's words, post-cinema is what happens when we view cinema as "one, relatively narrow band on a wide spectrum of simulation apparatuses" (315). This is a story about ontological instability, as the experiential guarantees of cinema dissolve and other audience expectations emerge.

What we propose is that none of these issues are new for translation, arguably the most unstable part of the cinematic ecology always characterized by degrees of contingency, redundancy, improperness, and informality. Situated at the coalface of cinema's "extraordinary internationalism" (O'Regan 94), translation in the form of subs, dubs, voiceovers, and ad hoc interpreting underscores the medium's difference and 
otherness "from itself" in particularly concrete, pragmatic terms. Typically identified as a post-production effect facilitating dissemination and dispersal, translation both epitomizes and pre-empts concepts of post-cinema. Today's online sub scene is a vivid example of this wider problematic.

In this chapter, we provide a descriptive analysis of the evolving technologies that underpin informal subbing and sub sharing today. We isolate certain protocols, platforms, and formats, such as BitTorrent and streaming video, exploring their connections to key moments in the development of subbing culture. This focus provides a means to unpack some of the broader social and technological shifts that shape post-cinematic media consumption. As Cardoso et al. note, before the ascendancy of streaming platforms, informal peer-to-peer (P2P) file sharing accounted for a quarter of all Internet traffic - a massive share. Increasingly, P2P activity is coalescing around language diversification, as multilingual publics become more visible and vocal, and underserved language communities find ways to intercept and redirect content flows. In this sense, the informal sub scene is emerging as a seminal site of participatory culture and audience agency. Ripped and DIY subs alert us to the unfulfilled promise and underutilized potential of new technologies to facilitate transcultural exchange, overcoming language barriers rather than re-instituting them via geoblocking and other territorially-bound regulatory strategies.

\section{Theorizing Screen Translation}

Subtitle sharing takes many different forms. Some websites are commercial, with obtrusive display ads and pop-ups. Others are proudly not-forprofit and community-focused. Some subs are ripped from DVD tracks and churned through Google Translate; others are created from scratch by fans. At its most communitarian, the sub scene points to the growing significance of translation as a mode of cultural participation, demonstrating the affordances of network technologies while rehearsing many of the tensions that typically characterize media convergence more broadly (Jenkins). Yet the practice of subbing also reiterates a destabilizing dynamic inherent to translation as a whole. As a mode of cultural production that literally makes "new works out of old" (Hemmungs Wirtén, "Swedish Subtitling" 131), screen translation is in many ways a precursor to YouTube mash-up and re-mix practices; it is naturally convergent, crossing borders and dismantling boundaries while feeding off the compromises and conflicts of the multimodal. 
Just as the concept of post-cinema speaks to cinema's location within a diverse spectrum of platforms, from iPhones to laptops and gaming consoles, screen translation has always relied upon technologies and techniques marked as "other" or "outside" cinema proper. Subtitles are typically seen as particularly non-cinematic, compromising the moving image experience by prioritizing static, printed text over action, and reading over viewing. Similarly, in the days of silent and early sound cinema, many popular modes of translation incorporated live performance, blurring boundaries between cinema and theatre. Travelling troupes of cinema "talkers" enacted a form of live dubbing, where actors positioned behind the projection screen (often a sheet) would perform synchronized lines of dialogue. ${ }^{1}$ In Japan, cinema narrators known as benshi or katsuben often received top billing over film stars. This art form outlasted the transition to sound and included a rich variety of forms and styles, including kakeai, which was inspired by kabuki theater and involved multiple katsuben sitting in a row in front of the audience, performing lines of dialogue together. ${ }^{2}$

The mixed-media practices of subtitling, behind-the-sheet talkers and kakeai point to instances of ontological instability that actually originate in cinema itself as a medium that brings together photography, performance, narrative, scriptwriting, sound recording, and a range of other technologies, genres, and forms. In this way, everyday practices of translation draw out the post-cinematic nature of all cinema-its internal hybridity and compulsion to spread. In facilitating such circulation and expansion, translation re-configures cinema according to diverse audience needs, expectations, and demands. At times, this shift appears empowering, as when audiences deliberately intercept and re-interpret foreign cultural references in order to comment on local politics and events. In China, for instance, a special type of fansub (fan-subtitling) practice known as $T u C a o$ often "comments on certain phenomena or current events in China via the translation of subtitles". At other times, cinema's re-alignment is forcefully restrictive, as when state regimes enforce heavy-handed censorship through strategic translation and mistranslation.

Fundamental to translation practices, convergence culture and fansubbing alike, the overlap between production and reception confuses notions of authorship, copyright, and intellectual property, as quickly became apparent during the first Berne Convention on international copyright in 1886, where "the author's exclusive right of translation, the author's right to authorize translations of his or her work as well as the right of the translator to his or her translation" became "la question 
internationale par excellence" (Hemmungs Wirtén, Cosmopolitan Copyright 18). ${ }^{4}$ As Hemmungs Wirtén explains, translation turns the author-reader relationship into a threesome "and sets in motion a contradictory and ongoing expansion of authorship, the repercussions of which we encounter almost daily in the present copyright wars" (Cosmopolitan Copyright 71). In this way, even the most faithful of translations remains inherently de-authorizing. Translation wrests control away from the author, whom it also risks betraying. In the process, translation suffers a loss of authority and cultural legitimacy, and is accorded a secondary, supplementary status ${ }^{5}$ that contributes to its devaluation, as documented by Lawrence Venuti.

As both original and derivative, creation and copy, translation repeatedly surfaces in Derrida's delineation of de-construction, acting as a leitmotif across multiple texts that foreground the "double bind" of language. ${ }^{6}$ For Derrida, translation cannot help but register the instability at the heart of all language and communicative systems. Language itself is thoroughly invested in conditions of production and reception, speaking and hearing, self and other-and it is this ambiguity that is brought to the fore through the compromises of translation, which Derrida terms both necessary and impossible ("Tours de Babel" 171). Just as translation de-stabilizes or "disarticulates" (De Man 84) originals by exposing their prosaic nature and contingencies, screen translation challenges the supposed purity of cinema, exposing the risky, contaminating processes of reproduction, circulation, and transformation upon which "originals" depend.

Here, finally, we arrive at the common thread that connects translation history with cinema history. From early cinema's "heyday" of rampant, widespread copying (Gaines), when exhibitors often took charge of translation themselves, ${ }^{7}$ through to the instabilities of today's digital, post-cinema environment, where the status of the "original" medium, text, or commodity is ever more in question, these histories can both be understood as stories of ad hoc, informal modes of practice in amongst more organized, professional, and institutional activities. Taking this quality seriously as a fundamental condition of both cinema and translation, we can now begin to understand today's proliferating infrastructures of digital subbing - the fast-moving ecology of websites, torrents and forums - as an extension, rather than a novel manifestation, of these informalities. When fans volunteer their services as amateur translators in diverse forums, from the TED Open Translation Project to Facebook and Subscene, they demonstrate the versatility and prevalence of the informal as a foundational element of cinema history. 
While professional subtitling and dubbing are subject to significant unsteadiness caused by shifting industry norms-ideological impositions, improvised solutions, and self-censorship, for example-this instability is exacerbated and intensified when subbing moves off-grid. Additionally, while subbing shares certain characteristics with professional practices, as we explore below in relation to continuities between DVD and BitTorrent, informal subbing often remains a step ahead, satisfying changing audience needs while pioneering new uses and abuses of emergent technologies. In this way, informal practices are complexly positioned in relation to market dynamics ${ }^{8}$ and are not necessarily either anti-market or culturally resistant. Rather, as Mattelart (746-47) notes with reference to pirate distribution, informal practices often replicate the social inequalities that bar access to official media, and are thus "inserted in a complex interplay of hegemonic relations at local, as well as at national and global levels".

In a convergent mediascape, it is often difficult to clearly distinguish professional from informal translation, as the two regularly overlap. Recently, both Netflix and American anime distributor Funimation have been caught using informal subs-in one case fansubs, and in another "ripped", pirated subs (Ernesto, "Anime Distributor", "Netflix Caught"). Additionally, the phenomenon of crowdsourced translation or "localization", so critical to the global success of web platforms like Twitter, LinkedIn, and Facebook, attests to the growing legitimacy of amateur, volunteer translation. ${ }^{9}$ Crowdsourced translation mobilizes decentralized networks to perform massive translation feats in fractional turnaround times-as organized communities of fans were doing, at a smaller scale, decades earlier. As streaming platforms and video-ondemand services create and respond to new types of media consumption, professional subtitling and dubbing are high on the agenda, as is locallanguage content production (Gottfried). Yet professional audiovisual translation isn't likely to absorb the prolific sub scene any time soon. This is because informal subbing is about more than translation alone. Amongst the sub scene's post-Babel babble, the message that rings the loudest speaks to the "access gaps" (Lee 1142) that structure global media products and their circulation. Professional audiovisual translation, on the other hand, remains largely caught within these gaps and the territorial market structures and boundaries upon which they are premised. 


\section{Subbing Ontologies: Video, DVD, Torrents, STreaming}

Having explored some of the conceptual affinities between cinema, postcinema, and translation past and present, we now zoom in to the micro level to look more closely at the technological parameters of the sub scene and its significance for screen culture broadly. In what follows we consider four technologically-defined moments in the evolution of informal subbing, related to video (VCRs and VHS tapes), DVD, BitTorrent, and streaming, and explore the particular ontology associated with each. Our aim here is to show, on the one hand, how a wave of successive subbing technologies has shaped and re-shaped informal screen translation practices, and on the other, how each of these technologies has participated in the decomposition and re-arrangement of the cinematic medium, prefiguring what we now call the post-cinema condition.

Our analysis begins in the age of home video. While informal translations have long been produced and circulated at the fringes of screen culture, by cinephiles, aesthetes, dissidents, and commercial pirates, the roots of today's digital subbing practices can be traced more precisely to the emergence of portable video and consumer genlock (generator locking) technology that allowed the synchronization of simultaneous video feeds (Fig. 8.1). Used by enthusiasts to superimpose computer-generated text over reel-to-reel videotapes and, later, video cassettes, ${ }^{10}$ the genlock became the premier subbing technology of its time, as Sean Leonard explains:

The essential hardware for fansubbing between 1989 and 1998 was a genlock, or generator locking device. This device enables a video machine, such as a TV, to accept two signals simultaneously. When operational, a genlock synchronizes an incoming video signal with computer output, enabling the overlay of subtitles in real time. The results of a genlock system were then recorded on another videocassette and distributed along a vast fan network. Many fansubbers incorporated time-synchronized VHS and S-VHS decks into their fansubbing systems; by the mid 90 s, these systems allowed for nearperfect timing and accuracy of subtitles and spoken dialogue. ("Progress" 10)

Genlocks, which could be connected to early home computers like the Amiga PC and the Macintosh, unleashed a wave of DIY video subbing. In the case of anime fan circuits, where subbing practices were especially sophisticated, videotape distribution circuits relied on fan-to-fan mail- 


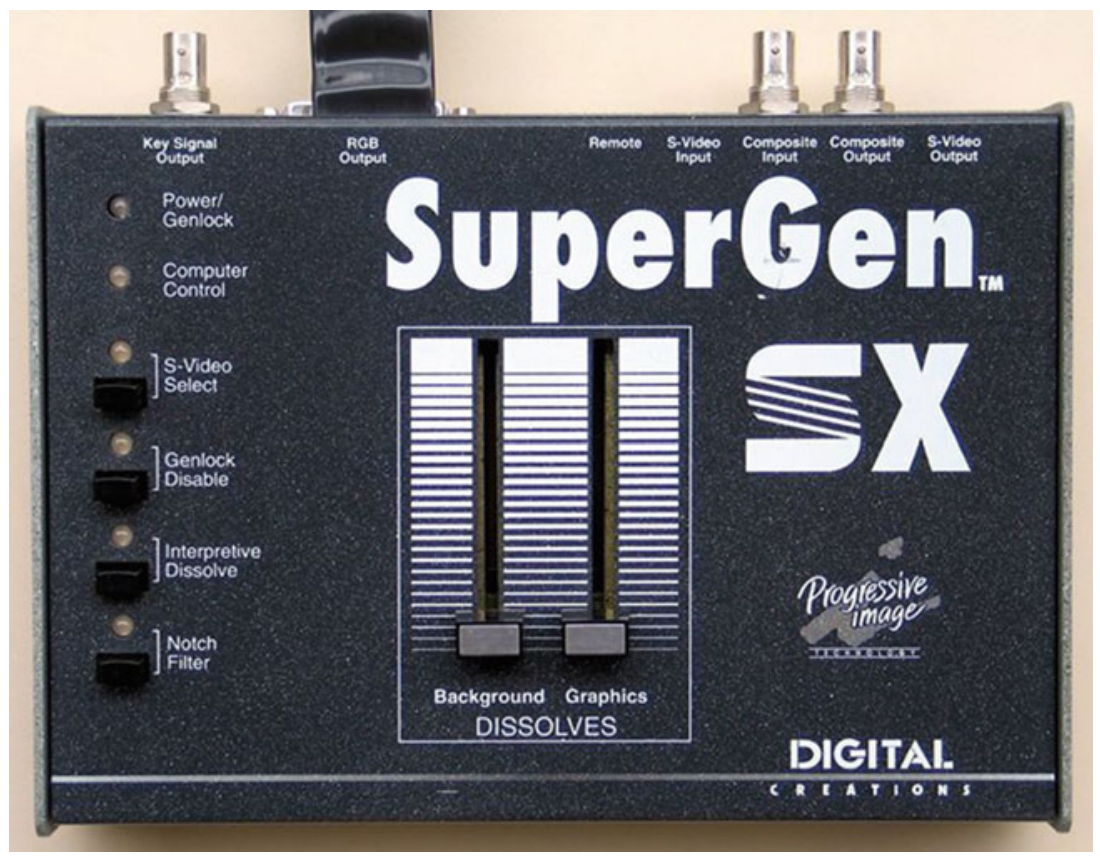

Fig. 8.1 The genlock — an essential technology for video-era subbing (Image credit: Daniel Rehn, CC license)

order distribution, with new programming supplied by American military officers stationed in Japan (Leonard, "Progress"). These distribution networks formed the basis for the legal anime markets that emerged later when Japanese media companies started selling into the US market. This moment of genlock-enabled fansubbing was pivotal in the history of audiovisual translation: henceforth, professional-looking subbing could, in theory, be done at home, though these efforts were admittedly laborintensive, difficult, and expensive (genlocks cost around US\$4,000 at the time). According to Leonard ("Celebrating"), fansubbing a single TV episode at this time would have taken over 100 hours.

Genlock subbing was about superimposition: text over video. Additional layers could be added but never removed. Text and video, once united, were inseparable. This palimpsest model of subbing was geared towards single-language translation, though in some cases tapes would acquire multiple layers as they moved through informal circuits, with new 


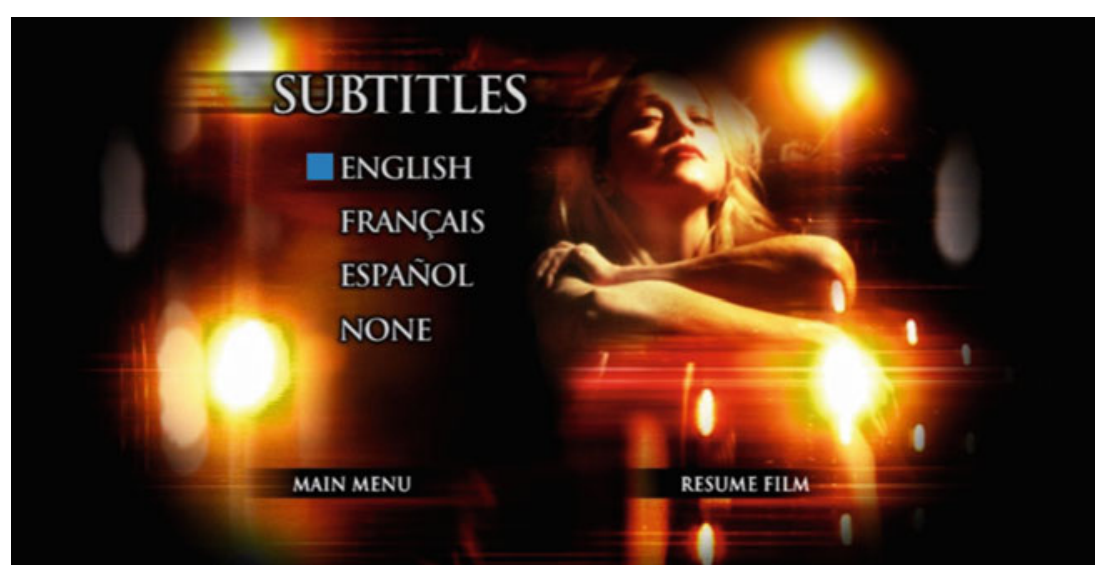

Fig. 8.2 The DVD subtitle menu-a typical set-up, from Abel Ferrara's Dangerous Game (1993)

languages added over the top of pre-existing ones. The anthropologist Brian Larkin recalls watching a Van Damme movie in northern Nigeria with "Chinese subtitles superimposed over Arabic ones, providing a visible inscription of the routes of media piracy" (296).

DVD players, which appeared in homes in the late 1990s, ushered in a different form of engagement with subtitles. The digital video disc format carried multiple language streams and audio tracks, which could be selected through the disc menu (Fig. 8.2) or the Subtitle and Language/Audio buttons on the remote control. DVDs typically had language selections that mirrored their DVD region, often requiring users-notably those in Region 2 (encompassing Western Europe, the Middle East, and Japan) - to cycle through lengthy lists before making their language choice. In pirate DVD circuits, one could find very eclectic language selections geared to the specificities of local markets and international trading routes. These subtitles were typically translated by students, or lifted from out-of-region DVDs with the help of extractor software. Popular ripping/burning freeware packages - such as DVD Shrink, first released in 2003 - could handle multiple subtitle and audio tracks, so creating multilingual DVDs was easy for pirates (Fig. 8.3).

The DVD and its functional separation of video, sound, and text formed the basis for later subbing innovations, which led to further disintermediation and re-combination of these elements. With the rise of 


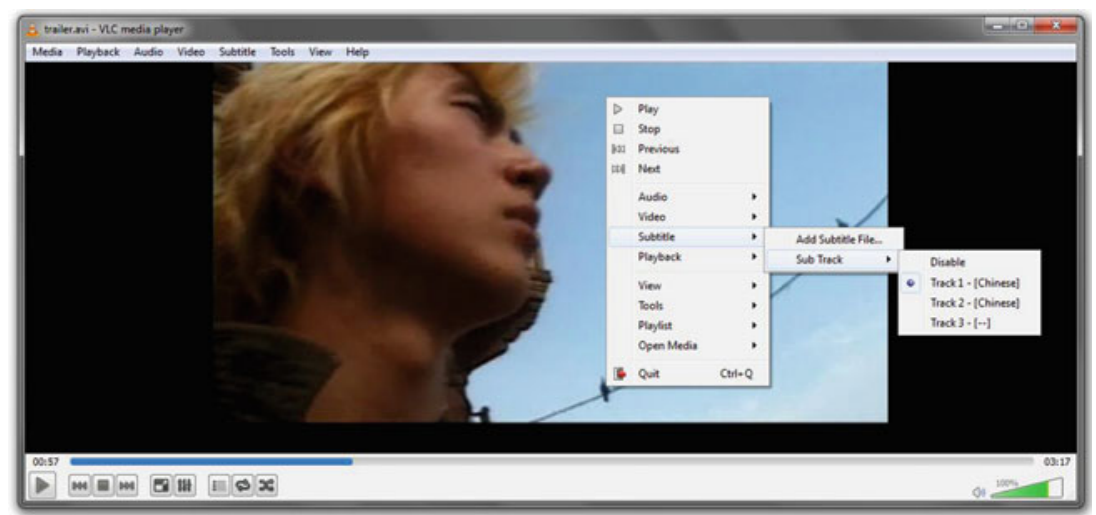

Fig. 8.3 Subtitle functionality on VLC Media Player re-mediates the DVD menu experience

BitTorrent in the mid-2000s, a new standard emerged: text-based subtitle files (in SRT and SUB formats), packaged together with pirated videos and distributed through BitTorrent. The other essential ingredient here was open-source media players, such as VLC Player, which allowed easy loading of downloaded subtitle files. Re-mediating the DVD aesthetic, these players invited the user to select from a DVD-like list of subtitle tracks (see Fig. 8.3). This period of Internet history also saw the emergence of more and more dedicated forums and sites for the exchange of SRT and SUB files, along with improved machine translation systems, such as Google Translate.

The BitTorrent scene is a mass-scale free economy-literally a free-forall-that extended and intensified the mobility of cinema across platforms. In this way, torrents moved subbing practices out of the space of cinema and TV and into the space of the Internet. Now liberated from discs, subtitle files became information to be exchanged like any other kind of data (Fig. 8.4). They shed their historical association with moving image culture and became a digital object-in-circulation. Henceforth, subbing technology was more accessible for people outside the audiovisual professions and niche fan networks alike. It had become an everyday technical practice.

This SRT/SUB model of sub sharing, associated with the BitTorrent era and premised on the functional separation of text and video, now co-exists alongside a number of new-generation translation technologies designed to work with on-demand streaming platforms. Streaming is distinct from 


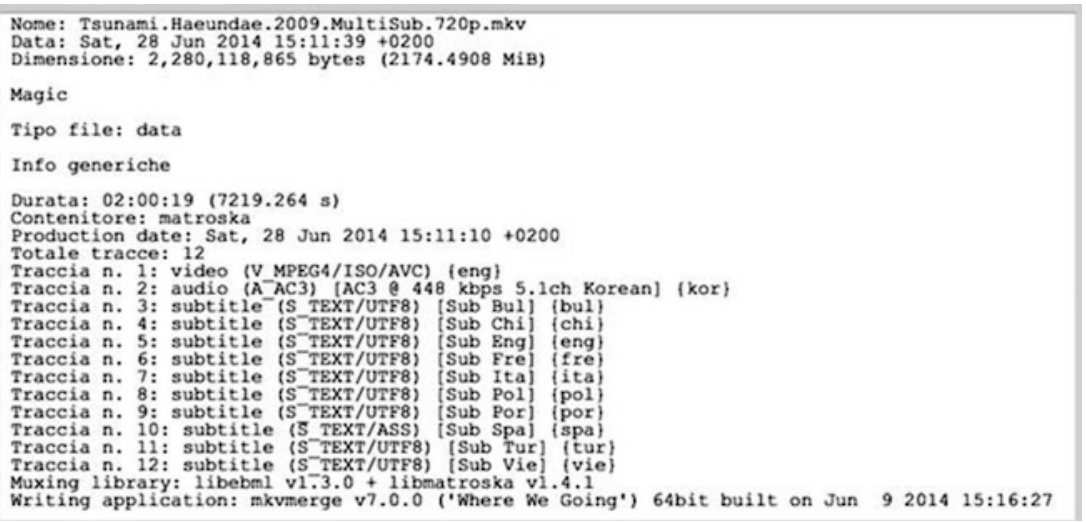

Fig. 8.4 Multiple subtitle tracks in a torrent file listing

downloaded media in the sense that it re-integrates translation into the user interface, recalling both the "unified" video experience as well as the multilingualism of the DVD. Characterized by commercial sites with userfriendly, social media-enabled interfaces that aspire to app-style simplicity, today's streaming platforms increasingly offer multiple sub and audio tracks, as well as closed captions for native language users.

YouTube has been experimenting with captioning technologies since 2006, introducing playable multiple-language subs capability in 2008 . Today, YouTube users who want to sub their own videos can upload text files encoded with dialogue and timings, or use YouTube's own in-platform subbing technology (simply typing in subs as the video plays). Netflix has also been investing in subbing; since 2010 its customers have been able to select between language subtitles or native-language captions on a growing number of films and TV shows, with the language menu changing according to the customer's IP location. Its SAMI (Synchronized Accessible Media Interchange) platform re-mediates the subtitle functionality of a DVD, enabling different overlays on top of the same video file (Fig. 8.5). ${ }^{11}$ Captioning and subbing of user videos is being actively promoted by these companies as part of their international expansion efforts, which are premised on making content appealing to users in as many nations as possible. YouTube in particular encourages its users to think of themselves as global producers by providing free analytics for each video that show its popularity in different countries, and partnering with professional translation 


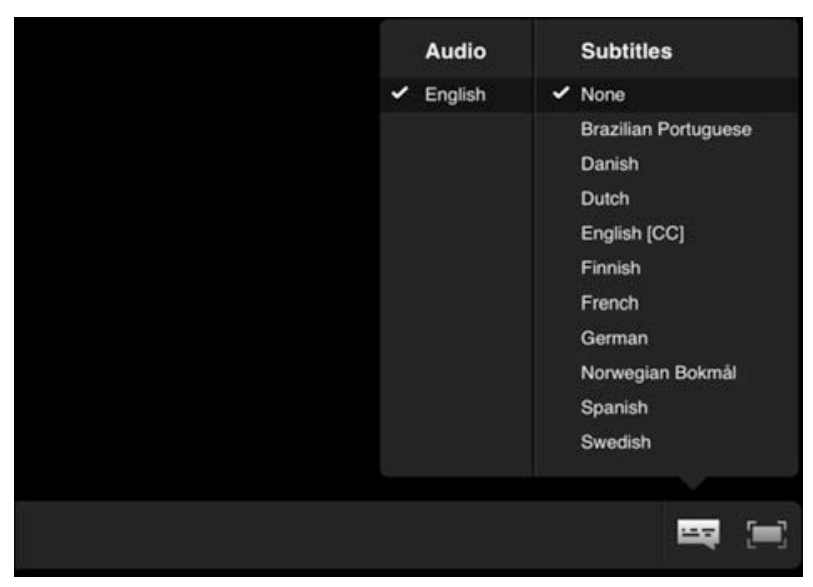

Fig. 8.5 Netflix subtitle options are also reminiscent of the DVD interface. Subtitle options vary widely according to content, license and region

companies who can be easily hired by creators through the YouTube platform. These initiatives are targeted towards semi-professional creators of original material, but YouTube's translation systems are also widely used for pirated material. Many popular Hong Kong movies, for example, can be watched in full on YouTube in numerous formats: English-language dubbed versions; subbed versions with burnt-in hardcoded subs; and newer uploads with multiple subtitle tracks that can be switched on or off as needed. Here we can see an example of convergence between formal and informal innovations and technologies, as ideas migrate from pirate culture to mainstream platforms and vice versa.

Another example is the emergence of Viikii (now Viki) in 2008-a "global TV" site with an innovative translation capability that streams free amateur subs in a multitude of languages. A dedicated Viki plug-in and subtitle editor enables multiple users to contribute subtitles at the same time. ${ }^{12}$ These subs are "edited and re-edited on the fly, wiki-style with those judged by the community to be most accurate getting prime display" (Upbin). Viki has popularized several innovations, including new translation interfaces, "type as you watch" functionality, browser-based translation, and timed comments. However, the real game-changer that allowed Viki to transition from class project to commercially oriented startup was its transformation into a commercial streaming platform with digital rights management, which enabled it to comply with copyright restrictions and 


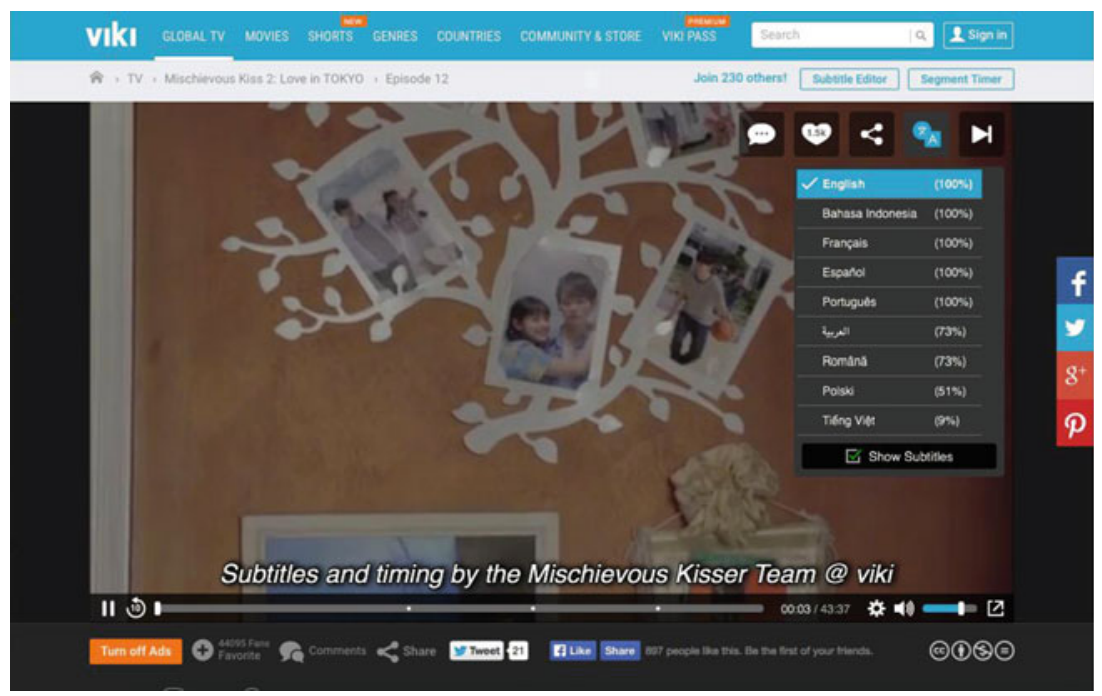

Fig. 8.6 The Viki interface, streaming Korean drama CHAngnansŭRŏN K'isŭ ("Playful Kiss", MBC-TV, Korea 2010), "Episode 1". Sub language options are displayed in a pop-up window on the right-hand side

negotiate licensing deals with major broadcasters and content producers such as the BBC, NBC Universal, and Asahi TV. By offering streamed access rather than downloads, Viki has been able to provide exclusivity windows on some content (Upbin), insert ads and share ad revenue with producers. Providing a "legal playground" (Hovaghimian) for piratestyle practices and new monetization opportunities, this model has since been adopted by countless other video sites, including the formerly illegal Crunchyroll (Denison; Ito). While the file-sharing culture that formed the basis of these ventures realizes the inbuilt potential of digitization to fully separate form and content, thereby facilitating widespread copying, it also constitutes a mode of media "socialization", demonstrating a desire for communal, shared modes of technological engagement now foregrounded in online streaming platforms like Viki and YouTube (Fig. 8.6).

As streaming platforms rise in popularity, potentially displacing torrents as the de facto distribution system for subbed content, the character of informal translation may be changing. The allure of streaming is that everything is already built into the platform-no need to download software or subs, or mess about with synchronization. Torrents direct users 
outwards, to the mind-hive, for subs and support; streamed subtitles keep you happily locked within the platform. In this sense we may be entering a new moment in subbing, premised on the linguistic capabilities of proprietary streaming platforms as opposed to the more distributed file-sharing culture of BitTorrent. But of course, this distinction between streaming and file sharing blurs at the margins. Hackers are forever finding ways to make one more like the other. Online conversion tools can convert SRT files into Netflix-readable DFXP (Distribution Format Exchange Profile) files so they can be played alongside Netflix-streamed content. ${ }^{13}$ And then there are popular pirate services like Popcorn Time, a BitTorrent-enabled media player fashioned to look like a streaming platform, which can be tweaked to play user-generated subtitles. Here, as elsewhere, ontological distinctions between subbing and distribution systems begin to blur, echoing the unstable relations between moving image technologies in the post-cinema environment.

\section{Conclusion}

This chapter began by asking what the current discussion about postcinema, characterized by anxiety about the uncertain status of the moving image in a multiplatform environment, might learn by looking sideways to the history of screen translation. As we have argued, today's ostensible crises of the cinematic medium are in fact pre-figured within translation history, in the sense that translation itself has long been characterized by the same qualities-informality, instability, contamination-that are said to characterize post-cinema. Digital network technologies simply intensify the inherent volatility of translation, as illustrated in our discussion of four eras of informal subbing shaped by the technological affordances of VHS tapes, DVDs, BitTorrent, and streaming platforms.

Today's networked sub-sharing culture is remarkable for the way it refines existing paradigms of participatory or prosumer culture. Indeed, the extraordinary agency and productivity of amateur subbers has garnered significant attention from media scholars already. But there is also a different kind of lesson here for film theory-a lesson about distribution. Media studies of distribution have tended to see it as a process of endless replication, in which content spreads across markets and platforms, colonizing space and time in a quasi-imperial manner. In many accounts there is an assumption that the content in question remains more or less the same, despite changes in format, quality, definition, and 
packaging. Informal subbing networks, however, foreground distribution as a process of overt transformation, shaped by diverse cultures, contexts, and languages. When digital re-mediation meets language transfer, we encounter circuits of distribution premised on difference rather than sameness. Distribution becomes the space in which textual difference is inscribed.

Here, the ontological instability of translation-its inherently deauthorizing and de-stabilizing dynamic - meets up with the technological (in)determinism of the post-cinematic. If digital distribution is by definition a post-cinematic process, then informal circulation via DIY subs and ripped SRT files foregrounds the additional layers of social difference, including language and location, that shape ground-level media access despite the ostensibly democratizing potential of network technologies.

A useful next step for researchers in the area of screen translation would be to explore linkages between the affordances of various technologies and the scale of particular kinds of translation activity. Empirical studies of the quantity, nature, form, and accessibility of translation on offer within sub scene forums, for example, might reveal a great deal about what this particular kind of network means in terms of its capacity to enhance or restrict linguistic diversity, or its relative capacity to assemble new audiences for minority-language films. As already mentioned, file sharing of subs involves a different set of technological skills or barriers compared with streaming, yet how such differences shape translation practices is a topic yet to be systematically explored. Such research would represent a necessary starting point for thinking about how informal subbing and sub sharing might contribute to cultural diversity, as well as textual de-stabilization.

\section{Notes}

1. See Altman 166-173; Klenotic.

2. See Komatsu 39; Anderson 272-273.

3. See Zhang 34.

4. See Braxton 204.

5. See Derrida, Ear of the Other, "Tours de Babel".

6. See Derrida, "Living On" 78-79, Ear of the Other 102.

7. See Broeren.

8. See Condry.

9. See McDonagh Dolmaya. 
10. See Patten 7.

11. In practice, the implementation of this multilingual system was more difficult than it sounds, due in part to the problems of Microsoft's Silverlight streaming platform (Netflix has since switched to HTML5). Complaints about the reliability of the system and the quality of the subs are common. The English closed captions on Netflix have been ridiculed for their error-prone nature. As one reporter writes, "Closed captions on Netflix's instant streaming service are loaded with nonsense characters, transcription errors, and dialogue so implausible that it's hard to believe they're actually transcription errors" (Christian).

12. See Dwyer, "Fansub Dreaming", "Multilingual Publics".

13. The distinction between streaming and download is also regularly blurred by user practices which switch between the two systems. Mendes Moreira de Sa (291) discusses how Brazilian fansubbers, or legenders, begin the translation process by watching live streams of TV shows through online channels like Justin TV, and then discuss them amongst the group in online chat forums, before downloading the video file through $\mathrm{P} 2 \mathrm{P}$ processes, and dividing and distributing it. She also notes that this process is often facilitated by the English subtitles that already come with the file in the form of closed captions for deaf and hard-of-hearing viewers.

\section{BIBLIOGRAPHY}

Altman, R. Silent Film Sound. New York: Columbia University Press, 2004. Print. Anderson, J. L. "Spoken Silents in the Japanese Cinema; or, Talking to Pictures: Essaying the Katsuben, Contextualizing the Texts." Reframing Japanese Cinema: Authorship, Genre, History. Ed. A. Nolletti and D. Desser. Bloomington and Indianapolis: Indiana UP, 1992. 259-311. Print.

Braxton, J. A. "Lost in Translation: The Obstacles of Streaming Digital Media and the Future of Transnational Licensing." Hastings Communication and Entertainment Law Journal 36.1 (2013/14): 193-216. Print.

Broeren, J. "The Titles are in Dutch - Which Makes it Quite Simple': Intertitles as an Agent of Appropriation in the Netherlands, 1907-1916." MA thesis. Utrecht University, 2008. Print.

Cardoso, G., et al. "P2P in the Networked Future of European Cinema." International Journal of Communication 6 (2012): 795-821. Web. 24 Feb. 2015 <http://ijoc.org/index.php/ijoc/article/view/693>. 
Christian, J. "How Netflix Alienated and Insulted its Deaf Subscribers." The Week. N.p., 23 Jan. 2014. Web. 24 Feb. 2015 <http://theweek.com/articles $/ 452181 /$ netflix-alienated-insulted-deaf-subscribers $>$.

Condry, I. "Dark Energy: What Fansubs Reveal about the Copyright Wars." Mechamedia 5: Fanthropologies. Ed. F. Lunning. Minneapolis: University of Minnesota Press, 2010. 193-208. Print.

De Man, P. The Resistance to Theory. Manchester: Manchester UP, 1986. Print.

Denison, R. "Anime Fandom and the Liminal Spaces Between Fan Creativity and Piracy." International Journal of Cultural Studies 14.5 (2011): 449-466. Print.

Derrida, J. The Ear of the Other: Otobiography, Transference, Translation. Trans. P. Kamuf and A. Ronell. Ed. C. McDonald. Lincoln and London: University of Nebraska Press, 1985. Print.

Derrida, J. "Living On / Border Lines." Trans. J. Hulbert. Deconstruction and Criticism. Ed. H. Bloom, et al. New York: Seabury Press, 1979. 75-176. Print.

Derrida, J. "Des Tours de Babel." Trans. J. F. Graham. Difference in Translation. Ed. J. F. Graham. Ithaca and London: Cornell UP, 1985. 165-207. Print.

Dwyer, T. "Fansub Dreaming on ViKi: 'Don't Just Watch But Help When You Are Free'." The Translator 18.2 (2012): 217-243. Print.

Dwyer, T. "Multilingual Publics: Fansubbing Global TV." Contemporary Publics. Eds K. Lee, D. Marshall, G. D'Cruz, and S. Macdonald. Basingstoke and New York: Palgrave Macmillan, 2016. 145-162. Print.

Ernesto. "Anime Distributor Dubs Using 'Pirated' Subs.” Torrent Freak. 21 Mar. 2011. Web. 2 Feb. 2015. <https://torrentfreak.com/anime-distributordubs-using-pirated-subs-110321/>.

Ernesto. "Netflix Caught Using 'Pirated' Subtitles in Finland." Torrent Freak. 19 Oct. 2012. Web. 2 Feb. 2015. <https://torrentfreak.com/netflix-caughtusing-pirated-subtitles-in-finland-121019/>.

Gaines, J. M. "Early Cinema's Heyday of Copying: The Too Many Copies of L'arroseur arosé (The Waterer Watered)." Cultural Studies 20.2-3 (2006): 227-244. Print.

Gao, K. "Crunchyroll CEO: Making Online Anime Pay: Interview with Kun Gao, Part 1.” ICv2. 15 Dec. 2008. Web. 24 Feb. 2015. <http://www.icv2.com/ articles/index_print.php?article_id=13922>.

Gottfried, M. "Cost in Translation: Expansion Challenge for Netflix as It Ventures Abroad." Wall Street Journal. 27 Oct. 2014. Print.

Hemmungs Wirtén, E. Cosmopolitan Copyright: Law and Language in the Translation Zone. Uppsala: Uppsala Universitet, 2011. Print.

Hemmungs Wirtén, E. "Swedish Subtitling Strike Called Off! Fan-to-Fan Piracy, Translation and the Primacy of Authorization." Amateur Media: Social, Cultural and Legal Perspectives. Ed. D. Hunter, et al. New York: Routledge, 2012. 125-36. Print. 
Hovaghimian, R. "Future of TV." The Korea Times. 10 May 2011. Web. 1 Oct. 2012.<http://www.koreatimes.co.kr/www/news/tech/2011/05/129_86778. html>

Hu, K. "Competition and Collaboration: Chinese Video Websites, Subtitle Groups, State Regulation and Market." International Journal of Cultural Studies 17.5 (2014): 437-51. Print.

Ito, M. "Contributors versus Leechers: Fansubbing Ethics and a Hybrid Public Culture." Fandom Unbound: Otaku Culture in a Connected World. Ed. M. Ito, et al. New Haven and London: Yale University Press, 2012. 179-204. Print.

Jenkins, H. Convergence Culture: Where Old and New Media Collide. New York: New York University Press, 2006. Print.

Jenkins, H., S. Ford, and J. Green. Spreadable Media: Creating Value and Meaning in a Networked Culture. New York and London: New York University Press, 2013. Print.

Klenotic, J. 'The Sensational Acme of Realism': 'Talker' Pictures as Early Cinema Sound Practice." The Sounds of Early Cinema. Eds. R. Abel and R. Altman. Bloomington and Indianapolis: Indiana UP, 2001. 156-66. Print.

Komatsu, H. "Mastering the Mute Image: The Role of the Benshi in Japanese Cinema." Iris 22 (1996): 33-52. Print.

Larkin, B. "Degraded Images, Distorted Sounds: Nigerian Video and the Infrastructure of Piracy." Public Culture 16.2 (2004): 289-314. Print.

Lee, H-K. "Participatory Media Fandom: A Case Study of Anime Fansubbing." Media, Culture \& Society 33.8 (2011): 1131-147. Print.

Leonard, S. "Celebrating Two Decades of Unlawful Progress: Fan Distribution, Proselytization Commons, and the Explosive Growth of Japanese Animation." UCLA Entertainment Law Review 12.2 (2005): 189-265. Print.

Leonard, S. "Progress Against the Law: Fan Distribution, Copyright, and the Explosive Growth of Japanese Animation." MIT Japan Program 4.2 (2004). Web. 24 Feb. 2015. <http://web.mit.edu/seantek/www/papers/progressdoublespaced.pdf>.

Lindgren, S. "Sub*culture: Exploring the Dynamics of a Networked Public." Transformative Works and Cultures 14 (2013). Web. 24 Feb. 2015. <http:// dx.doi.org/10.3983/twc.2013.0447>.

Mattelart, T. "Audiovisual Piracy, Informal Economy, and Cultural Globalization." International Journal of Communication 6 (2012): 735-750. Print

McDonagh Dolmaya, J. "The Ethics of Crowdsourcing." Linguistica Antverpiensia New Series 10 (2011): 97-110. Print.

Mendes Moreira de Sa, V. “The Collaborative Production of Amateur Subtitles for Pirated TV Shows in Brazil." Piracy: Leakages from Modernity. Ed. M. Fredriksson and J. Arvanitakis. Duluth, MN: Litwin Books, 2014. 285-306. Print.

Naficy, H. “Theorizing 'Third-World' Film Spectatorship." Wide Angle 18.4 (1996): 3-26. Print. 
O'Hagan, M. "Evolution of User-Generated Translation: Fansubs, Translation Hacking and Crowdsourcing." The Journal of Internationalization and Localization 1.1 (2009): 94-121. Web. 24 Feb. 2015. <https://benjamins. com/\#catalog/journals/jial.1.04hag/fulltext>.

O’Regan, T. "Australian Cinema as a National Cinema." Film and Nationalism. Ed. A. Williams. New Brunswick and London: Rutgers University Press, 2002. 89-136. Print.

Orrego-Carmona, D. "Subtitling, Video Consumption and Viewers: The Impact of the Young Audience." Translation Spaces 3 (2014): 51-70. Print.

Patten, F. Watching Anime, Reading Manga: 25 Years of Essays and Reviews. Berkeley, CA: Stone Bridge Press, 2004. Print.

Pérez González, L. "Fansubbing Anime: Insights into the 'Butterfly Effect' of Globalisation on Audiovisual Translation." Perspectives: Studies in Translatology 14.4 (2006): 260-77. Print.

Stam, R. "Post-Cinema: Digital Theory and the New Media." Film Theory: An Introduction. Ed. R. Stam. Malden, MA: Blackwell, 2000. Print.

Upbin, B. "Viki Unlocks the Other $85 \%$ of Television." Forbes: Tradigital Blog. N.p., 8 Dec. 2010. Web. 24 Feb. 2015. <http://blogs.forbes.com/bruceupbin/2010/12/08/viki-unlocks-the-other-85-of-television>.

Venuti, L. The Translator's Invisibility: A History of Translation. London: Routledge, 1995. Print.

Zhang, X. "Fansubbing in China." MultiLingual Jul./Aug. (2013): 30-37. Print. 